\section{Estudo \\ cabebate}

em Testão

Plamejamento
Revista Estudo \& Debate, Lajeado, v. 26, n. 1, 2019. ISSN 1983-036X

DOI: http://dx.doi.org/10.22410/issn.1983-036X.v26i1a2019.1874

\title{
RECICLAGEM DE RESÍDUOS OLEOSOS: AÇÁO DE SENSIBILIZAÇÃO AMBIENTAL COM ALTERNATIVAS DE RECICLAGEM PELA PRODUÇÁO ARTESANAL DE SABÃO
}

\author{
Patricia Inês Schwantz ${ }^{1}$, Joyce Cristina Gonçalvez Roth², Evelise Fonseca dos Santos ${ }^{3}$, \\ Daniela Mueller Lara ${ }^{4}$
}

\begin{abstract}
Resumo: Nos últimos anos a preocupação da sociedade com problemas relacionados ao meio ambiente tem alavancado esforços para realização de práticas e processos que garantam a sustentabilidade das futuras gerações. Acredita-se que a mudança de comportamento possibilitará a alteração deste cenário a partir da conceituação do termo "sustentabilidade", partindo da premissa de que tópicos relacionados a reciclagem e ao reaproveitamento de resíduos serão propulsores para a mudança e melhoria deste cenário atual. Neste sentido, o objetivo dessa pesquisa é discutir os fatores agravantes das problemáticas ambientais apresentando alternativas de reutilização do óleo vegetal por meio da produção artesanal de sabão e sensibilização dos alunos de uma escola de ensino fundamental e médio no município de Santa Cruz do Sul/RS. A metodologia consiste em uma análise de dados obtidos por questionários, palestras e oficinas de produçáo artesanal de sabão. Foi possível constatar que o ambiente escolar é propício para identificação de agentes transformadores e multiplicadores das açóes elencadas durante a realização deste trabalho. A educaçáo ambiental de crianças e jovens aceleram o processo de mudança de hábitos do restante da populaçáo, que muitas vezes desconhecem alternativas e práticas sustentáveis. Concluiu-se que a educaçáo ambiental é dependente da adesão voluntária, proporcionando aos alunos vivências e contribuiçóes para reduzir danos causados por açóes da população em geral.
\end{abstract}

Palavras-chave: Educação Ambiental. Sabão artesanal. Resíduos oleosos.

1 Graduanda em Engenharia de Bioprocessos e Biotecnologia, Universidade Estadual do Rio Grande do Sul (UERGS) em Santa Cruz do Sul.

2 Mestre em Tecnologia Ambiental, Universidade de Santa Cruz do Sul (Unisc); Professora Assistente de Engenharia Ambiental, Universidade Estadual do Rio Grande do Sul (UERGS).

3 Doutora em Química, Universidade Federal do Rio Grande do Sul (UFRGS); Professora Adjunta de Química, Universidade Estadual do Rio Grande do Sul (UERGS) em Santa Cruz do Sul.

4 Doutora em Ambiente e Desenvolvimento; Professora Adjunta de Engenharia Ambiental, Universidade Estadual do Rio Grande do Sul (UERGS) em Alto da Serra Botucaraí Soledade.

-- Artigo Recebido em 01/06/2018. ACeito em 01/03/2019. -- 


\title{
RECYCLING OF OILY RESIDUES: ACTION OF ENVIRONMENTAL AWARENESS WITH RECYCLING ALTERNATIVES BY HANDMADE PRODUCTION OF SOAP
}

\begin{abstract}
Currently the concerning society with environmental problems has leveraged efforts to carry out practices and processes that ensure sustainability of future generations. It is believed that the change in behavior will make it possible to change this position by concept of the term "sustainability", starting from the premise that topics related to recycling and waste reuse will be thrusters for the change and improvement of this current scenario. Therefore, the purpose this study is to discuss the aggravating factors of the environmental problems introducing alternatives of reuse of vegetable oil through the production of handmade soap and sensitization of the students of a primary and secondary school in the municipality of Santa Cruz do Sul/RS. The methodology consists of an analysis of data obtained by questionnaires, lectures and handmade soap production workshops. It was possible to analyze that the school environment is favorable sustainable development with transforming and multipliers agents of the actions listed during the accomplishment of this work. Environmental education of children and young people accelerates the process of changing the habits of the rest of the population, who are often unknown of sustainable alternatives and practices. It is concluded that environmental education is dependent on voluntary access, providing students with experiences and contributions to reduce damages caused by actions of the general population.
\end{abstract}

Keywords: Environmental Education. Vegetable oil. Handmade Soap. Oily waste.

\section{INTRODUÇÁO}

A conduta da sociedade contribui sistematicamente para o aumento dos impactos ambientais, que se agravam nos centros urbanos devido ao crescimento e a maior concentração da população (EL-DEIR, 2014). Conforme Philippi e Pelicioni (2005) a percepção por parte da sociedade acerca dos problemas ambientais vem ocorrendo de maneiras diferentes por todas as classes sociais.

Isso pode ser exemplificado pelos agravantes ambientais vivenciados nas últimas décadas, os quais nos colocam diante de situações que desafiam a construção de um novo modelo de vida que consiga trazer em seu cerne a perspectiva da sustentabilidade do planeta com inúmeros benefícios sociais. Entretanto é perceptível que a mudança de comportamento, a partir da sensibilização e conceituação do termo "sustentabilidade" no contexto escolar, pode introduzir expectativas de alteração deste cenário.

Desde a década de 60 as questóes ambientais são pauta de discussóes. Entretanto, somente em 1972, na Conferência de Estocolmo, na Suécia, ocorreram importantes mudanças relacionadas a esta temática. Ficou estabelecido o "Plano de Ação Mundial" e, em particular, a recomendação acerca do Programa Internacional de Educação Ambiental. Desde então, a Educação Ambiental (EA) passou a ser considerada como campo de ação pedagógica, adquirindo relevância e vigência internacional. (SOUZA, 2000).

Considerando que a EA é estabelecida pela relação do homem com o meio ambiente, concentrando-se na preservação, conservação e utilização de forma equilibrada dos recursos naturais disponíveis, se torna possível projetar um contexto sociocultural e sociopolítico equiparado com a sustentabilidade ambiental. $\mathrm{O}$ conceito de sustentabilidade atende a um conjunto de variáveis interdependentes, e deve ter a capacidade de integrar as questóes sociais, culturais, energéticas, econômicas e ambientais. 
Conforme Carvalho (2016), a sustentabilidade é um termo que surge a partir da interação do ser humano com o mundo, e, a construção do conceito de desenvolvimento sustentável consolidou-se durante a Cúpula Mundial sobre o Desenvolvimento Sustentável, da ONU, realizada em Joanesburgo, África do Sul, em 2010. A Declaração de Joanesburgo foi assinada por representantes de 191 países e estabeleceu que o desenvolvimento sustentável se baseia em três pilares: desenvolvimento econômico, desenvolvimento social e proteção ambiental.

Os três pilares da sustentabilidade são alusão dos aspectos ambiental, social e econômico, os quais devem interagir de forma integrada, para satisfazer o conceito. Segundo Munck et al. (2012), o pilar econômico refere-se ao impacto das organizaçóes sobre as condiçóes econômicas, ou seja, representa a geração de riqueza pela e para a sociedade, por meio do fornecimento de bens e serviços. O pilar ambiental refere-se à conservação e ao manejo dos recursos naturais, tornando-se necessário que a organização procure minimizar os impactos negativos e ampliar os positivos, tanto em processos de entrada quanto de saída. Já o pilar social refere-se ao alcance da igualdade e da participação de todos os grupos sociais na construção e na manutenção do equilíbrio do sistema, compartilhando direitos e responsabilidades.

Nesse sentido, discutir questóes associadas à problemática dos resíduos sólidos são fundamentais para o (re)estabelecimento da qualidade do meio ambiente. A aplicação e execução destes conceitos são viáveis e efetivos quando trabalhados interdisciplinarmente, apresentando impacto positivo na aprendizagem e multiplicação da ação no ambiente escolar.

Ainda nessa prerrogativa, observa-se que muito esforço tem sido despendido na busca por alternativas de reutilização dos resíduos sólidos oriundos das atividades humanas. Diversas pesquisas têm demonstrado o emprego destes rejeitos na produção de biodiesel e também na produção de sabão.

Tendo em vista que a Educação Ambiental no ambiente escolar permite o desenvolvimento social, possibilitando a transformação de comportamentos, e, diante dos problemas gerados através do descarte incorreto de resíduos oleosos, a realização de um trabalho interligado de ambos possibilita a reduçáo dos impactos ambientais. Ainda, considerando-se que a escola é a fonte provedores do conhecimento e os membros do ambiente escolar (alunos, professores e funcionários) sendo os multiplicadores de açóes, visou-se capacitar seres humanos capazes de alterar o cenário atual reduzindo os problemas em relação ao descarte incorreto de resíduos oleosos residenciais, e consequentemente minimizando os impactos ambientais.

Neste sentido, buscou-se no presente estudo, conduzir a sensibilização a respeito da coleta seletiva de óleos residuais domésticos resultantes de processos de fritura e demonstrar processos de reciclagem para esse resíduo, atribuindo-lhe valor agregado. $\mathrm{O}$ escopo deste estudo foi estabelecido com o intuito de capacitar e sensibilizar os alunos, professores e funcionários, provocar a mudança de comportamento e mostrar uma alternativa de reciclagem de óleos e gorduras gerados em residências, possibilitando uma fonte de renda alternativa. 
Este trabalho foi uma iniciativa da Universidade Estadual do Rio Grande do Sul (UERGS) em parceria com uma escola estadual de ensino médio (E. E. E. M. Santa Cruz), ambas localizadas no município de Santa Cruz do Sul/RS. Foram abordadas e executadas alternativas de reutilização do óleo vegetal através da produção artesanal de sabão visando contribuir para alavancar a sustentabilidade do município, apostando no efeito multiplicador, na mudança de hábitos das famílias e da comunidade por meio da EA.

\subsection{Educação ambiental e resíduos oleosos}

Conforme a Política Nacional de Educação Ambiental - Lei no 9795/1999 (Art. 1º), entendem-se por Educação Ambiental (EA):

\footnotetext{
Os processos por meio dos quais o indivíduo e a coletividade constroem valores sociais, conhecimentos, habilidades, atitudes e competências voltadas para a conservação do meio ambiente, bem de uso comum do povo, essencial à sadia qualidade de vida e sua sustentabilidade.
}

Diante deste conceito, fica evidente que EA é uma dimensão da educação que permite o desenvolvimento social, com perspectivas de modificação do cenário ambiental a partir de uma visão multidisciplinar. A escola é uma instituição social que tem a finalidade de socializar o ser humano, além de contribuir para o desenvolvimento de outras habilidades. Além disso, assume papel na sensibilização do ser humano para o convívio com o meio ambiente.

A aplicação da EA no ambiente escolar também é assegurada pela Política Nacional do Meio Ambiente - Lei no 6.938/1981 que institui no artigo $2^{\circ}$, inciso X, a necessidade de promover a "educação ambiental a todos os níveis de ensino, inclusive a educação da comunidade, objetivando capacitá-la para participação ativa na defesa do meio ambiente". Assim, a EA nasce como um princípio e um instrumento da política ambiental.

Abordar a temática ambiental tem sido um dos principais desafios do processo educacional, sobretudo sob o viés de uma Educação Ambiental crítica, contextualizada na realidade dos estudantes, conforme CAMBOIM \& BARBOSA (2012). A inclusão da EA nas escolas possibilita que este tema seja levado pelos alunos até suas casas, ensinando familiares e pessoas que não tiveram o conhecimento e esclarecimento sobre questóes ambientais relacionadas aos resíduos sólidos.

Os resíduos sólidos são definidos pela Norma Brasileira NBR 10004/04, da Associação Brasileira de Empresas de Tratamento de Resíduos (ABETRE) como:

\footnotetext{
Aqueles resíduos nos estados sólido e semi-sólido, que resultam de atividades da comunidade de origem industrial, doméstica, hospitalar, comercial, agrícola, de serviços e de varrição. Ficam incluídos nesta definição os lodos provenientes de sistemas de tratamento de água, aqueles gerados em equipamentos e instalaçôes de controle de poluição, bem como determinados líquidos cujas particularidades tornem inviável o seu lançamento na rede pública de esgotos ou corpos de água, ou exijam para isso soluçôes técnicas e economicamente inviáveis em face a melhor tecnologia disponível.
} 
Conforme dados da Pesquisa Nacional de Saneamento Básico (PNSB/IBGE) (2000), a coleta de resíduos sólidos residenciais e comerciais representa 94,44\% em área urbana, dos quais $78 \%$ são caracterizados como domésticos. Esses incluem restos de alimentos, produtos de higiene pessoal, óleo de cozinha, embalagens, entre outros.

Os óleos e gorduras se destacam pela produção e destinação incorreta. No Brasil, estima-se que a produção dessa classe de resíduos seja de três bilhôes de litros por ano, dos quais cerca de $2,5 \%$ é reutilizado. O restante é indevidamente descartado pela população e indústrias em solos, corpos d'água, rede de esgotos, ou ainda, incinerados (FILHO et al., 2013).

Considerando a expansão na área de alimentos como principal fonte geradora desse resíduo, especificamente o óleo de cozinha, fica evidente a importância da responsabilidade compartilhada e da logística reversa para sua reciclagem. Logo, a produção artesanal de sabão agrega-se aos princípios da Política Nacional de Resíduos Sólidos (2010) e torna-se uma interessante alternativa para minimizar os impactos causados pelo óleo vegetal.

Conforme Pitta Junior et al. (2009), o descarte destes resíduos em corpos hídricos, em função da sua imiscibilidade com a água e sua inferior densidade, leva a formação de uma película sobre a água, dificultando a troca de gases com a atmosfera, e diminuindo a concentração de oxigênio dissolvido. Por consequência, há interferência nas condiçóes naturais do corpo hídrico, remetendo a morte de peixes e da vida aquática em geral, além da depreciação da qualidade das águas.

A EA e os resíduos oleosos são conceitos que, se trabalhados de forma interligada, promovem a transformação de comportamento associados a redução dos impactos ambientais. Neste sentido, Pinho e Andrade (2017) realizaram um estudo com alunos de uma escola municipal propondo a reutilização do óleo de fritura através da produção de sabão, mobilizando a comunidade escolar para a questáo da responsabilidade social. Neste estudo foi constatado a mudança de hábitos dos alunos e reduçâo da poluição no ambiente local e adjacentes, porém, os autores reforçam que a educação ambiental vai além da sensibilização da população, sendo necessário a prática continua da ação.

No mesmo sentido, Ribeiro et al. (2018) avaliaram a conscientização em relaçáo ao desenvolvimento sustentável através do procedimento de descarte dos resíduos oleosos de restaurantes comerciais. O estudo constatou que a maioria dos envolvidos estão sensibilizados com a questão da sustentabilidade e também com o descarte correto dos resíduos oleosos, porém, ressaltam a importância da continuidade de açôes semelhantes.

Por outro lado, Costa et al. (2015) realizaram um estudo com alunos de uma escola municipal visando sensibilizar a respeito dos danos causados ao meio ambiente pelo uso e descarte inadequado de óleo vegetal, e apresentaçáo de alternativas de reciclagem deste resíduo, e concluíram que mesmo sendo realizado ações de conscientização, alguns alunos ainda não estavam sensibilizados com a problemática ambiental causada pelos resíduos oleosos.

Entretanto, desde 2005, no município de Santa Cruz do Sul, a Associação dos Fumicultores do Brasil (AFUBRA) coloca em prática uma ação de coleta de óleo em parceria de escolas públicas e privadas e instituiçôes filantrópicas dos estados do PR, SC e RS, onde 
posteriormente, estas instituiçôes, com base no volume doado, podem retirar produtos em suas lojas, tais como, máquinas de corte, ferramentas entre outros. Os óleos são utilizados para a produção de biodiesel, proporcionando uma destinação adequada sem poluir o meio ambiente (AFUBRA, 2016).

\section{2 Óleos e gorduras}

Os óleos e gorduras são substâncias insolúveis em água, de origem animal ou vegetal, ou mesmo microbiana, formados predominantemente por ésteres do glicerol, conhecidos como triacilgliceróis, produtos resultantes da esterificação entre o glicerol e ácidos graxos (MORETTO; FETT, 1998). As estruturas do glicerol e dos triacilgliceróis são representadas na Figura 1.

Figura 1 - Estrutura do a) glicerol e b) triacilglicerol (R1, R2 e R3: radicais )

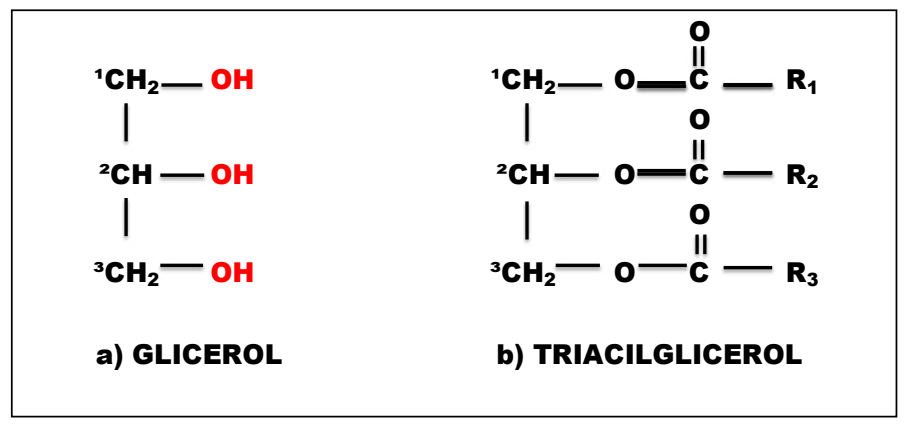

Fonte: Autores (2018).

Os óleos vegetais são formados predominantemente por ácidos graxos que possuem insaturaçóes em suas cadeias carbônicas, conferindo caráter líquido à temperatura ambiente. As gorduras, ao contrário, de origem animal são sólidas à temperatura ambiente, uma vez que possuem os componentes ácidos graxos de cadeia carbônica com poucas, ou nenhuma instauração (FENNEMA, 2000). O produto poderá ser um óleo ou gordura dependendo dos constituintes ácidos graxos, onde as cadeias carbônicas estão representadas por R1, R2 e R3.

Essas substâncias são matérias-primas para a fabricação de sabóes juntamente o hidróxido de sódio ou potássio (soda cáustica ou potássica). O processo industrial é bastante simples, mas o produto também pode ser obtido artesanalmente. Atualmente consumimos uma enorme quantidade de produtos derivados de sabóes e detergentes. Por esse motivo, saber como essas substâncias são produzidas, como agem e como são degradadas pela natureza, torna-se fator importante para que nossa interação com o meio ambiente seja mais madura e consciente.

O sabão é um produto formado pela reação de saponificação de óleos e gorduras com bases orgânicas ou inorgânicas. As matérias graxas empregadas na fabricação de sabóes são: os óleos ou azeites e as gorduras animais (banha ou sebo). O "óleo de fritura" se enquadra perfeitamente como matéria-prima para a produção de sabão, propiciando um destino final 
a este rejeito. Chama-se saponificação, a reação química que produz o sabão, representada na Figura 2.

Figura 2 - Reação de obtenção de um sabão.

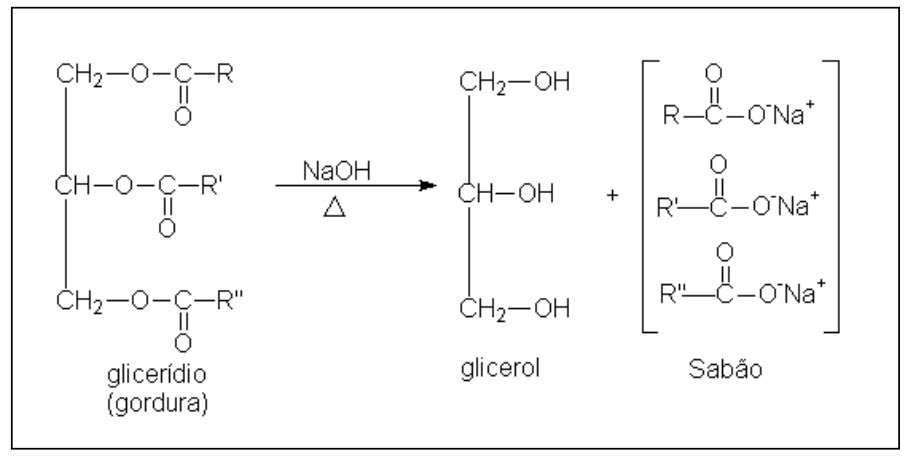

Fonte: Autores (2018).

Conforme a Companhia de Saneamento Básico do Estado de São Paulo - Sabesp (2018), um litro de óleo vegetal pode contaminar até vinte e cinco mil litros de água, pois, as substâncias deste resíduo são insolúveis em água e, quando despejadas nos cursos d' água, causam descontrole do oxigênio e a morte de peixes e outras espécies. Ainda, quando o óleo vegetal é descartado no solo, há contaminação e intervenção na biota terrestre.

Gomes et al. (2013) reforçam ainda que, o óleo e a gordura vegetal, por não serem biodegradáveis, levam muito tempo para se diluírem no ambiente quando descartados incorretamente. Quando estes resíduos são descartados no solo, matam a vegetação e os microorganismos, extinguindo o húmus, originando infertilidade da área, podendo atingir o lençol freático, inutilizando os poços da regiáo de entorno. Por outro lado, se jogados no esgoto, irão comprometer o funcionamento das estaçóes de tratamento, podendo acarretar a interrupçáo do funcionamento desse serviço.

\section{METODOLOGIA}

A fase inicial dos estudos foi marcada pelo levantamento de informaçóes e de uma revisão bibliográfica sobre o tema. A metodologia foi baseada em um estudo qualitativo e quantitativo através do emprego de questionários exploratórios, da realização de palestras e de oficinas para a produção artesanal de sabão.

As atividades realizadas envolveram alunos de séries iniciais, ensino fundamental e nível médio do turno diurno da Escola Estadual de Ensino Médio Santa Cruz, na cidade de Santa Cruz do Sul/RS, totalizando cerca de 700 alunos. Porém, a coleta de dados através dos questionários náo pode ser realizada de forma virtual, uma vez que a escola possuía limitaçóes em relação a computadores e internet. Sendo assim, os questionários foram impressos e depois tabulados e interpretados em forma de gráficos. Apesar das limitaçóes citadas, houve a participação efetiva do corpo docente, funcionários e alunos, possibilitando resultados satisfatórios na pesquisa. 
De forma geral, o trabalho constituiu-se das seguintes etapas:

- Diagnóstico inicial: Foi realizada a aplicação de um questionário constituído de 10 perguntas sobre o tema (Anexo 1). O mesmo foi aplicado aos alunos das séries finais do ensino fundamental e aos alunos do ensino médio, totalizando 290 alunos. Essas respostas foram avaliadas e a partir delas, um diagnóstico inicial foi elaborado.

- Palestras educativas: Após uma análise do diagnóstico inicial, foram realizadas palestras educativas sobre o tema. Durante os encontros os alunos foram orientados a respeito da importância do reuso e reciclagem dos resíduos gerados pela populaçáo bem como sua relevância no que diz respeito à escassez de recursos naturais, enfatizando os impactos causados pelos resíduos oleosos nas matrizes ambientais e apresentando diferentes alternativas de reduzir estes danos. Nestas palestras participaram todos os alunos da escola totalizando cerca de 700 alunos.

- Pesquisa e seleção da receita de sabão: Foram realizados diferentes testes para a seleção da receita, as quais tinham como reagentes a soda cáustica, água morna e óleo vegetal residual de frituras, porém elas se diferenciavam pela adição ou não de álcool na formulação. Os critérios levados em consideração para a escolha da receita foram a viabilidade econômica, a capacidade de produção de espuma e o pH conforme exigência da resolução normativa no1/78 da Anvisa. Não foram feitos testes químicos de acidez, ou iodo para caracterizar este óleo, sendo analisados apenas os aspectos físicos, tais como: viscosidade, cor, odor e partículas em suspensão. Durante a realização das práticas foram utilizados todos os equipamentos de proteção individual (EPIs) conforme as regras de segurança. As amostras foram acompanhadas diariamente observando o tempo de endurecimento e a capacidade de emulsificação do sabão. Após 10 dias, foram realizadas as medidas de $\mathrm{pH}$ das amostras, indicadores de papel obtendose o valor de basicidade adequada $(\mathrm{pH}=11)$ conforme resolução da Anvisa. Os testes de emulsificação foram realizados com pequenas amostras do sabão (1g). As amostras foram dissolvidas em água, ácido acético (vinagre) e solução de bicarbonato e observação da formação de espuma e o tempo de duração.

- Oficinas de produção de sabão e de confecção de embalagens: Uma vez escolhida e testada a receita, realizaram-se as oficinas de produção de sabão e de confecção de embalagens na escola. A preparação do sabão envolveu as turmas de terceiros anos do ensino médio, em torno de 110 alunos. Já a oficina de confecção das embalagens foi realizada com as turmas de quinto ano do ensino fundamental, cerca de 70 alunos. Para as embalagens utilizou-se a parte interna de rolos de papel higiênico dobrada em suas extremidades. Após as oficinas, foi adicionada a descrição da receita utilizada para viabilizar a produção do sabão aos alunos e a comunidade. Os reagentes e materiais necessários para receita: 250 gramas de soda cáustica, $500 \mathrm{ml}$ de água morna, 1 litro de óleo saturado, 1 balde de plástico, 1 pá de madeira/cabo de vassoura, 1 caixa forrada com plástico ou formas variadas, 1 máscara, 1 par de luvas. $\mathrm{O}$ modo de fazer: Misture a soda com a água morna no balde mexendo até que fique incolor. Após, adicione o óleo com cuidado e 
continue mexendo lentamente por cerca de 30 a 40 minutos, até que a mistura obtenha ponto de fio. Então, coloque na caixa/formas e deixe em local reservado para secar.

- Questionário final: Após as atividades, aplicou-se um questionário final (Anexo 2) para a análise e avaliação do projeto. Este continha 12 perguntas abordando o tema e as atividades executadas ao longo do projeto. Participaram desta etapa 294 alunos das turmas participantes.

- Divulgação do projeto a comunidade: A última etapa consistiu em integrar a comunidade local a esta atividade, incentivando a criação de um programa permanente de coleta e reciclagem de óleo dentro do ambiente escolar. A ação estimulou a produção artesanal de sabão como benefício ao meio ambiente e também como uma fonte alternativa de renda para as famílias. A divulgação foi realizada através do jornal e blog da escola.

\section{RESULTADOS E DISCUSSÃO}

Com a revisão bibliográfica realizada no início deste trabalho constatou-se a relevância e atualidade do tema abordado. Costa et al. (2015) realizaram um estudo semelhante em uma escola de Jaciara no Mato Grosso, sugerindo a produção de sabão líquido artesanal a partir de óleo de fritura e paralelamente desenvolveu atividades de sensibilização ambiental. Da mesma forma, Lima et al. (2014) visaram conscientizar a comunidade escolar de uma escola estadual da rede pública de Porto Velho, Rondônia, sobre a necessidade de reutilizar o óleo de cozinha como alternativa para amenizar os impactos causados por este, quando descartado de forma incorreta no meio ambiente, e, como forma de reutilização do óleo de cozinha, propuseram a produção de sabão.

Além destes, são inúmeros os trabalhos relacionados ao reaproveitamento de óleos residuais encontrados na literatura. Nota-se que, as instituiçóes de educação e as administraçóes públicas estão buscando educar ambientalmente a população. Os trabalhos analisados são realizados em escolas, comunidades e instituições sempre iniciam com o processo de arrecadação dos óleos provenientes de diferentes estabelecimentos e posterior processamento visando reduzir o descarte incorreto que causa danos ao meio ambiente. Em alguns casos, a ciência química é abordada com alunos, relacionando o conteúdo com aspectos sociais, econômicos e ambientais do contexto em que estão inseridos os estudantes.

A interpretação do questionário inicial mostrou que a grande maioria dos estudantes questionados reconhece a importância do cuidado no descarte de resíduos e da necessidade de uso racional dos recursos naturais. Para $85 \%$ dos entrevistados as questóes ambientais são consideradas "interessantes" ou "importantíssimas". Cerca de 70\% dos alunos não se sentem diretamente responsáveis pelo impacto de suas açóes e de suas famílias sobre a qualidade do meio ambiente. Este resultado foi posteriormente discutido nas palestras salientando a relevância do papel individual nas açóes ambientais.

Durante todo o trabalho a questão ambiental foi prioritária e sempre se buscou um processo de sensibilização e mudança de hábitos. Seguindo essa premissa, os questionários foram aplicados online, utilizando o recurso Google Drive. Como as séries iniciais não 
possuem acesso para responder os questionários aplicados com as ferramentas acima citadas, somente alunos a partir do $6^{\circ}$ ano do ensino fundamental responderam aos questionários.

Durante as palestras educativas (Figura 3), foram discutidos inúmeros impactos associados às açóes antrópicas, enfatizando àqueles causados pelo óleo de cozinha. Paralelamente alternativas de reciclagem deste resíduo foram discutidas.

Figura 3 - Palestra educativa sobre a temática ambiental

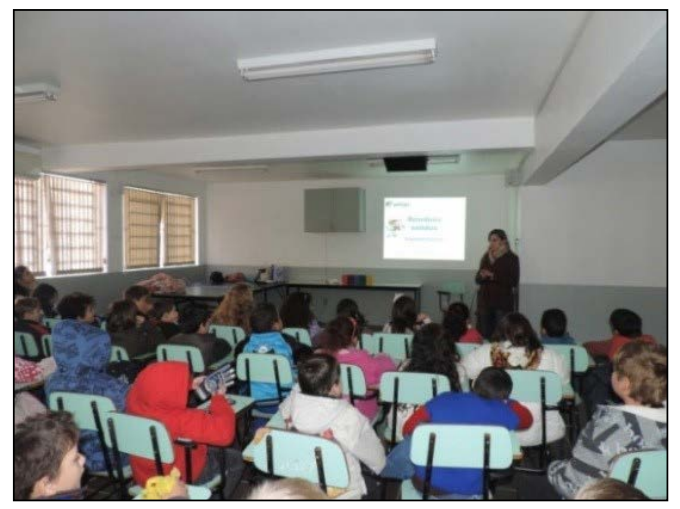

Fonte: Autores (2018).

Além do sabão e detergente líquido, o óleo vegetal residual pode servir de matéria prima para outros produtos como óleo para engrenagens, glicerina automotiva, tintas, etc. Os alunos mostraram interesse e foram participativos, questionando sobre o tema abordado, contribuindo com exemplos e consideraçóes.

Em relação ao desenvolvimento da prática em laboratório para a escolha da melhor receita, percebeu-se que aquelas formuladas com o reagente álcool, levaram um maior tempo de maturaçáo e náo tiveram o mesmo efeito de emulsificação comparado com as receitas que foram feitas na ausência desse regente. A receita selecionada destacou-se pela produçáo de espuma e elevada capacidade de limpeza. Além disso, a receita é viável economicamente, devido à ausência de álcool na sua formulação. A reprodutibilidade e facilidade deste método foram levadas em consideração para a posterior fabricaçấo durante as oficinas.

Anterior a prática (Figura 4) foi realizada uma abordagem teórica do tema: gorduras/ óleos; funçóes químicas, e a reação. Ressaltou-se a importância do uso de Equipamento de Proteção individual - EPI assim como o prévio conhecimento dos produtos químicos utilizados na receita. 
Figura 4 - Oficina de produção de sabão

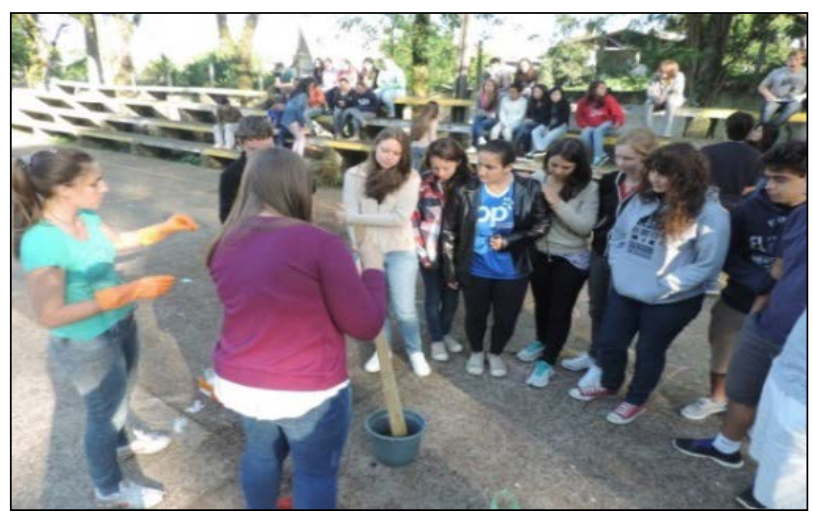

Fonte: Autores (2018).

$\mathrm{Na}$ oficina de confecção das embalagens também foram discutidos temas relevantes sobre a reciclagem e a busca incessante por materiais alternativos que minimizem os impactos ambientais. Nesta oficina a criatividade dos alunos foi importantíssima para a concretização das embalagens confeccionadas (Figura 5).

Figura 5 - Embalagem confeccionada para armazenagem do sabão produzido

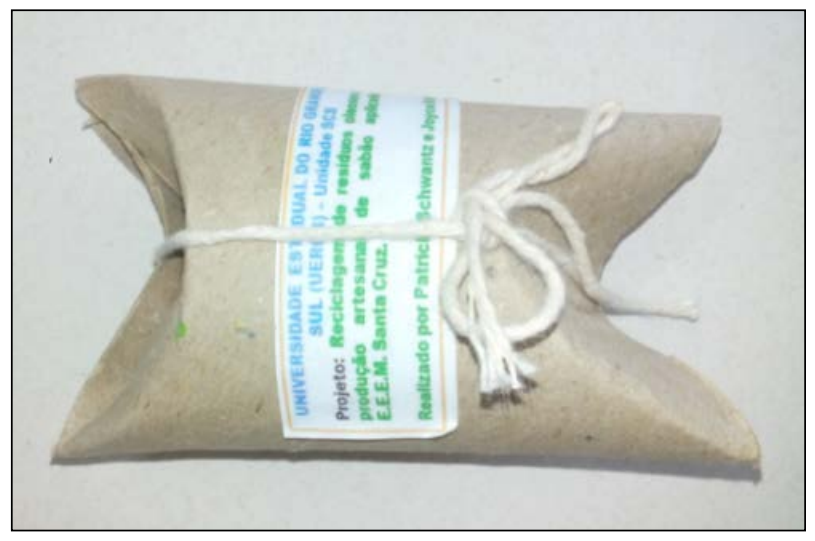

Fonte: Autores (2018).

A análise do questionário final revelou que mais de $60 \%$ dos alunos diz saber separar os resíduos corretamente e que conhecem os impactos causados pelo descarte inadequado do óleo de cozinha no meio ambiente. Contudo, uma grande parte dos alunos não acredita que suas atitudes fazem parte e somam à poluiçáo gerada e aos danos ao meio ambiente. Acredita-se que o principal fator que influencia nesta descriçáo é oriundo da falta de maturidade com práticas e adoção de sistemas relacionados aos aspectos ambientais. Dentre os alunos, mais de $80 \%$ acharam importante um projeto como o realizado e afirmaram terem ampliado seus conhecimentos sobre o assunto a partir das palestras realizadas. 
Posterior às oficinas, as amostras de sabão junto com a receita foram distribuídas à comunidade escolar. Nesta etapa tomou forma o efeito multiplicador da ação integrando a família e a sociedade. Mesmo que a reprodução da receita não seja efetivada por todos os alunos em suas residências, a açáo do projeto alertou e sensibilizou sobre o descarte adequado e os efeitos dele sobre o ambiente.

A educaçáo ambiental de crianças e jovens aceleram o processo de mudança de hábitos do restante da população, que muitas vezes desconhecem alternativas e práticas sustentáveis. Conforme afirmação de Paulo Freire (BRANDÃO, 1991), "ninguém educa ninguém, ninguém conscientiza ninguém, ninguém se educa sozinho", ou seja, a educação condiciona-se a adesão voluntária.

Ainda foi sugerida a criação de um programa permanente de coleta e reciclagem de óleo, estimulando a produção artesanal de sabão como benefício ao meio ambiente e também como uma fonte alternativa de renda. Também se sugere a continuidade de açôes de sensibilização por parte da gestão escolar com alunos professores e funcionários proporcionando maior efetividade dos trabalhos iniciados neste projeto, pois se acredita que a participação de atividades permanentes permite ao aluno maior facilidade de adaptação e inclusão em sua rotina diária, resultando na mudança de hábitos.

Bonotto e Carvalho (2016) apresentam relatos de que a criança pode e deve ser exposta às sensibilizaçôes e problematizaçóes ambientais no contexto escolar desde os primeiros anos, reforçando que as açóes devem ser contínuas. No mesmo sentido, Diaz (2002) já mencionava que a educaçáo é a chave para renovar os conceitos sociais, desenvolver a consciência possibilitando desde a mudança de atitudes individuais até a participação na resolução de problemas sociais e mundiais.

Ao final deste estudo, foi possível perceber que, apesar das limitaçôes encontradas, os objetivos foram alcançados possibilitando a capacitação e sensibilização dos alunos, professores e funcionários, observando-se a mudança de comportamento a partir da alternativa de reciclagem de óleos e gorduras gerados em residências como uma fonte de renda alternativa.

\section{CONSIDERAÇÓES FINAIS}

Através da execução deste projeto a comunidade da E. E. E. M. Santa Cruz obteve esclarecimentos sobre questóes ambientais e puderam ver na prática uma alternativa simples e eficaz de reutilizaçáo de óleos de cozinha residuais. Foi destacada a importância da conscientização de todos sobre o grande impacto na poluição das águas pelo descarte inadequado do óleo, onde cada um deve ser responsável pela preservação do meio ambiente. Mesmo que o resíduo doméstico seja gerado em pequenas quantidades o prejuízo pelo descarte incorreto é imenso.

A prática de preparação de sabão a partir de óleo residual levou para a sala de aula a aplicação de conteúdos de química e educação ambiental. O sabão obtido é destinado para limpeza doméstica não sendo adequado para utilização na higiene pessoal. Com o domínio da técnica de preparação do sabão, poderão também ser adicionados outros ingredientes à 
formulação, como corantes e essências, agregando mais valor ao produto que pode também servir como item decorativo e gerar renda extra para a escola e as famílias.

Devido ao grande interesse demonstrado e o envolvimento por parte dos professores e alunos nas atividades, a aplicaçáo e manutençáo de um programa ambiental de coleta de óleo e produção artesanal de sabão é visto como atividade promissora do conhecimento e sensibilização voluntária, além da multiplicação do conhecimento na sociedade.

\section{REFERÊNCIAS:}

AFUBRA. Associação dos Fumicultores do Brasil. Biodiesel. Notícias. 2016. Disponível em: https://afubra.com.br/noticias/10594/escolas-e-instituicoes-que-coletaram-oleosaturado-recebem-premios-financeiros.html. Acessado em 18 de abril de 2018.

ASSOCIAÇÃO BRASILEIRA DE EMPRESAS DE TRATAMENTO DE RESÍDUOS -ABETRE. Classificação de resíduos sólidos - Norma ABNT NBR 10.004:2004. São Paulo - SP, agosto/2006. Disponível em: http://www.abetre.org.br/. Acesso em 25 de fevereiro de 2018.

BONOTTO, D.M.B.; CARVALHO, M.B.S.S. Educação Ambiental e valores na escola: buscando espaços, investindo em novos tempos [online]. São Paulo: Cultura Acadêmica, 175 p., 2016.

BRANDÃO, C. R. O que é método Paulo Freire. São Paulo: Brasiliense, 1991.

BRASIL. Lei 6.938, de 31 de agosto de 1981.Dispóe sobre a Política Nacional do Meio Ambiente, seus fins e mecanismos de formulação e aplicação, e dá outras providências.

BRASIL. Lei 9.795, de 27 de abril de 1999.Dispóe sobre a educação ambiental, institui a Política Nacional de Educação Ambiental e dá outras providências.

BRASIL. Lei 12302, de 02 de agosto de 2010. Institui a Política Nacional de Resíduos Sólidos, altera a lei 9605 de 12 de fevereiro de 1998 e dá outras providências. Diário Oficial da União, 03 de agosto de 2010.

CAMBOIM \& BARBOSA. Estratégias de Educação Ambiental por meio da atuação da Com-Vida: vivências em uma escola do Recife-PE. Holos - RN. Ano 28, v. 1, p. 124-136. mar 2012.

CARVALHO, Fábio. Os 3 pilares da sustentabilidade. FAAC Gestáo e Treinamento. 2016. Disponível em https://www.faacconsultoria.com.br/single-post/2016/09/25/Os-3Pilares-da-Sustentabilidade. Acesso em 07 de março de 2018.

COSTA, Daniela Alves da; LOPES, Gilmeire Rulim; LOPES, José Roberto. Reutilização do óleo de fritura como uma alternativa de amenizar a poluição do solo. Revista

Monografias Ambientais - REMOA. v.14, p.243-253. 2015. 
EL-DEIR, Soraya Giovanetti. Resíduos sólidos: perspectivas e desafios para a gestáo integrada. Recife, 1. ed, EDUFRPE. 2014.

FENNEMA, Owen. R. Química de los alimentos. $2^{\text {a } . e d . ~ Z a r a g o z a: ~ A c r i ́ b i a, ~} 2000$.

FILHO, Sérgio Thode. SANTOS, Aline Santiago da Silva. ALMEIDA, Thuanny Moraes de. SILVA, Elmo Rodrigues da. Tecnologia ambiental aplicada ao gerenciamento e processamento do óleo vegetal residual no estado do Rio de Janeiro. Revista Eletrônica em Gestáo, Educaçáo e Tecnologia Ambiental - REGET/UFSM, Santa Maria - RS, v. 15 n. 15, p. 3026-3035, out. 2013.

GOMES, Amanda Pereira; CHAVES, Talita Freire; BARBOSA, Juliana Nobrega; BARBOSA, Edimar Alves. A questão do descarte de óleos e gorduras vegetais hidrogenadas residuais em indústrias alimentícias. XXXIII Encontro Nacional de Engenharia de Produção. Bahia. 2013.

IBGE, Instituto Brasileiro de Geografia e Estatística. Pesquisa Nacional de Saneamento Básico. Ministério de Planejamento, orçamento e gestão, 2008. Disponível em: http:// www.ibge.gov.br/home/estatística/população/condiçãodevida/pnsb/pnsb.br. Acesso em 22/03/2018.

LIMA, Renato Abreu; PAZ, Eloisa Santana; SOUZA, Jaqueline Rodrigues; BRAGA, Adriana Guimarães Silva. Aplicação do Projeto Didático-Pedagógico "Sabão Ecológico" em uma Escola Pública de Porto Velho - RO. Revista Eletrônica em Gestáo, Educaçáo e Tecnologia Ambiental - REGET/UFSM, Santa Maria - RS, v. 18, n. 3, p.1268-1272, set/dez. 2014.

MORETTO, Eliane; FETT, Roseane. Tecnologia de óleos e gorduras vegetais na indústria de alimentos. São Paulo, Varela Editora e Livraria Ltda, 1998.

MUNK, Luciano; BANSI, Ana Cláudia; DIAS, Barbara Galleli; OLIVEIRA, Flávio Augusto Cella de. Em busca da sustentabilidade organizacional: a proposição de um framework. Revista Alcance. Vol. 20, n. 04, p. 460-477 - out/dez. 2013.

PARDO-DÍAZ, A. Educaçáo Ambiental como projeto. 2.ed. Porto Alegre: Artmed, 2002.

PHILIPPI, J. A.; PELICIONI, M. Educaçáo Ambiental e Sustentabilidade. Barueri, SP. Manole, 2005.

PINHO, Maria José Souza; ANDRADE, David Dias de. Educação ambiental através da reciclagem de óleos residuais em escolas na cidade de Itíuba-BA. Revista Online Educaçáo Ambiental em Açáo. Ano XVI, Set-Nov 2017, n. 61. 2017. 
PITTA JUNIOR, O. S. R.; NOGUEIRA NETO, M. S.; SACOMANO, J. B.; LIMA, A. Reciclagem do óleo de cozinha usado: uma contribuição para aumentar a produtividade do processo. Key elements for a sustainable world: Energy, water and climate change. 2ns International Workshop - Advences in Cleaner Production. São Paulo, Brasil, p. 1-10, maio 2009.

RIBEIRO, Lucas Eduardo; et al. Desenvolvimento sustentável: Descarte de resíduos oleosos em restaurantes comerciais de Maringá - PR. Revista Livre de Sustentabilidade e Empreendedorismo, v. 3, n. 5, p. 187-211, set-out, 2018.

SABESP. Companhia de Saneamento Básico do Estado de São Paulo - Sabesp. 2018. Disponível em: $<$ http://site.sabesp.com.br/site/interna/Default.aspx?secaoId=82>. Acessado em 27/10/2018.

SOUZA, Renato Santos de. Entendendo a questáo ambiental: temas de economia, política e gestáo do meio ambiente. Santa Cruz do Sul/ RS, EDUNISC, 2000 


\section{ANEXO 1:}

\section{Questionário inicial:}

1) Qual é a sua idade?

( ) 6 a 8 anos () 9 a 11 anos ( ) 12 a 14 anos ( ) 15 a 17 anos ( )acima de 18 anos

2) Você reside em zona:

( ) urbana ( ) Rural

3) Onde você mora existe coleta de lixo?

( ) Sim ( )Não

4) Na sua casa/apartamento, ocorre alguma separação de resíduos?

( ) Sim ( )Não

5) Quanto a separação, você sabe como separar os residuos orgânicos e inorgânicos? ( ) Sim ( )Não

6) Dentre os impactos ambientais citados abaixo, enumere de 1 a 5 qual o seu nível de preocupação, sendo que 1 é o mais grave e o 5 é o menos significante:
2
3

1

5

Desmatamento

Queimada

Poluição do $\mathrm{Ar}$

Poluição da

Água

7) Você se considera responsável de alguma forma por algum dos impactos citados acima? ( )Sim - Desmatamento ( ) Sim - Queimada ( ) Sim - Poluição do ar ( ) Sim - Poluição da água ( ) Não

8) Você acredita que as ações ambientais desenvolvidas pela sua escola podem influenciar no cenário ambiental do seu município?

( )Sim ( )Não

9) Quanto ao óleo de cozinha, depois de utilizado em sua casa, qual o destino dado?

( ) Despejando no ralo da pia ( ) Armazenado em garrafas pet ou outro recipiente ( ) Reutilizado para fazer sabão ( ) Não sabe

10) As questões ambientais ocupam cada vez mais espaço nas pautas de discussão da sociedade; mas o que você acha a respeito do assunto?

( ) Chato ( ) Não tem nada a ver comigo ( ) Interessante ( ) Importantíssimo 


\section{ANEXO 2:}

\section{Questionário final:}

1) Qual é a sua idade?

() 9 a $11 \operatorname{anos}($ ) 12 a 14 anos () 15 a 17 anos ()Acima de 18 anos

2) Você reside em zona:

() Urbana () Rural

3) Quanto aos resíduos gerados em sua residência, você sabe separá-los? () $\operatorname{Sim}($ )Não

4) Na sua casa/apartamento, você faz a separação dos residuos? () $\operatorname{Sim}($ )Não

5) Você se considera responsável por gerar algum dos impactos abaixo listados? () Sim, desmatamento () Sim, queimadas ( ) Sim, poluição água ()Sim, poluição solo ( )Não

6) Você conhece os danos que o óleo de cozinha, após utilização, pode causar ao meio ambiente? () $\operatorname{Sim}$ ( )Não

7) Quanto ao óleo de cozinha após a utilização, qual destino você acredita ser correto?

() Reutilizado para fazer sabão () Armazenado em garrafa PET ou em outro recipiente ( ) Despejar no ralo da pia ou no solo ( ) Não sabe

8) Se você soubesse transformar o óleo usado em sabão, faria o processo em sua casa? ( ) $\operatorname{Sim}($ )Não

9) Qual a motivação para transformar o óleo usado em sabão? ( dê nota de 1 a 3, sendo 1 importantíssimo, 2 importante, 3 menos importante)

\begin{tabular}{|c|c|c|}
\hline & 1 & 2 \\
\hline Econômico & $r$ & \\
\hline $\begin{array}{l}\text { Colaborar com } \\
\text { Meio Ambiente }\end{array}$ & $\mathrm{C}$ & 8 \\
\hline Curiosidade & $c$ & $c$ \\
\hline
\end{tabular}

10) Se a escola implantasse um programa permanente de Educação Ambiental voltado para a coleta do óleo usado e produção do sabão, você participaria ativamente dessa atividade?

() $\operatorname{Sim}()$ Não

11) Em sua opinião você acha importante um projeto como esse? () Sim, pois colabora com a preservação do meio ambiente() Sim, pois pode ser uma fonte de renda ()Não

12) A palestra desenvolvida pela UERGS, integrante do projeto "Produção artesanal de sabão", ampliou de alguma forma os seus conhecimentos sobre o assunto?

() $\operatorname{Sim}($ )Não 